УДК 537.9

\title{
ДИНАМИКА ИЗМЕНЕНИЯ ЭЛЕКТРИЧЕСКИХ СВОЙСТВ В ЗАВИСИМОСТИ ОТ ТЕМПЕРАТУРЫ СИСТЕМЫ ПОЛИБУТИЛЕНТЕРЕФТАЛАТ - ПОЛИЭТИЛЕН
}

Акаева Маднат Магомедовна к.т.н., доцент ФГБОУ ВО «Чеченский государственный университет» Академия наук ЧР

\begin{abstract}
Аннотация:
Измерены

диэлектрические

свойства

полибутилентерефталата

и полимер

полимерных

смесей

полибутилентерефталат - полиэтилен методом диэлектрических потерь с помощью моста переменного тока, погрешностью не более 5\%. Установлено, что влиянию температуры, подвержены диэлектрическая проницаемость $\varepsilon^{\prime}$ и тангенса угла диэлектрических потерь $\operatorname{tg} \delta$ ПБТ и полимер - полимерные смеси ПБТ - ПЭ.
\end{abstract}

Ключевые слова: полиэтилен, диэлектрическая проницаемость, диэлектрические потери, полибутилентерефталат, полимер.

\section{INFLUENCE OF A HIGH-DISPERSED Fe / FeO MIXTURE ON THE MECHANICAL PROPERTIES OF POLYAMIDE}

\section{Akaeva Madnat Magomedovna}

\begin{abstract}
The dielectric properties of polybutylene terephthalate and polymerpolymer mixtures of polybutylene terephthalate - polyethylene were measured by the method of dielectric losses using an AC bridge, with an error of no more than 5\%. It is established that the permittivity $\varepsilon^{\prime}$ and the tangent of the dielectric loss angle $\operatorname{tg} \delta$ of PBT and polymer - polymer mixtures of PBT - PE are affected by temperature.

Key words: polyethylene, permittivity, dielectric loss, polybutylene terephthalate, polymer.

Наиболее сложно получить полимерные материалы с необходимыми характеристиками с помощью синтеза, затрачивается много энергии и ресурсов.
\end{abstract}


В связи с этим растет ассортимент полимерных композиционных материалов (ПКМ) формируемых их смесей или сплавов промышленных полимеров. Наиболее удобным и экономически выгодным получения новых ПКМ с необходимыми свойствами является смешение двух или более термопластов [1, c. 20]. Данный способ сопровождается сложными физико-химическими явлениями под действием временно-температурно механических полей. Большинство базовых полимеров несовместимы друг с другом, изменяя структуру и морфологию компонентов, можно получать смеси и сплавы с требуемыми эксплуатационными характеристиками. Структура, молекулярный дизайн из двух и более компонентов ПКМ весьма сложны и только в последнее время появляются публикации, раскрывающие физико-химические, структурно-морфологические и другие стороны этой проблемы [2, с. 51, 3, с. 127]. Одной из проблем прямого смешения промышленных инженерных полимеров, среди которых одним из ведущих является полибутилентерефталат (ПБТ), с крупнотоннажными полиолефинами (ПО) является неполярность макромолекул последних [3, с. 35]. Необходимая совместимость в полимерполимерных системах может быть достигнута при минимизации межфазного натяжения и усилении адгезии между фазами. Такой способ позволяет при незначительных изменениях морфологии и строения фаз формировать композиции с повышенными деформационно-прочностными свойствами, термическими характеристиками, позволяющими значительно расширить спектр применения ПБТ в составе КМ [4].

Для правильного применения ПКМ в качестве диэлектриков или полупроводников необходимо знания их электрических свойств, понимание динамики изменений этих свойств, при модификации матрицы полимера и условий эксплуатаций. Изучена температурная зависимость диэлектрической проницаемости $\varepsilon^{\prime}(l)$ и тангенса угла диэлектрических потерь $\operatorname{tg} \delta$ полимерполимерных композиций в интервале концентраций полиэтилена (ПЭ) от 2,5 до10 \% . Композиции готовились экструзией при температуре 220 - $230{ }^{\circ} \mathrm{C}$.

Диэлектрические характеристики ПБТ и полимер-полимерных смесей полибутилентерефталат - полиэтилен (ПБТ-ПЭ) определяли методом диэлектрических потерь с помощью моста переменного тока с цифровым отсчетом марки Р-5058 при частоте $10^{4}$ Гц в интервале температур от 20 до $250{ }^{\circ} \mathrm{C}$. Погрешность в измерениях тангенса угла диэлектрических потерь не более $5 \%$. 


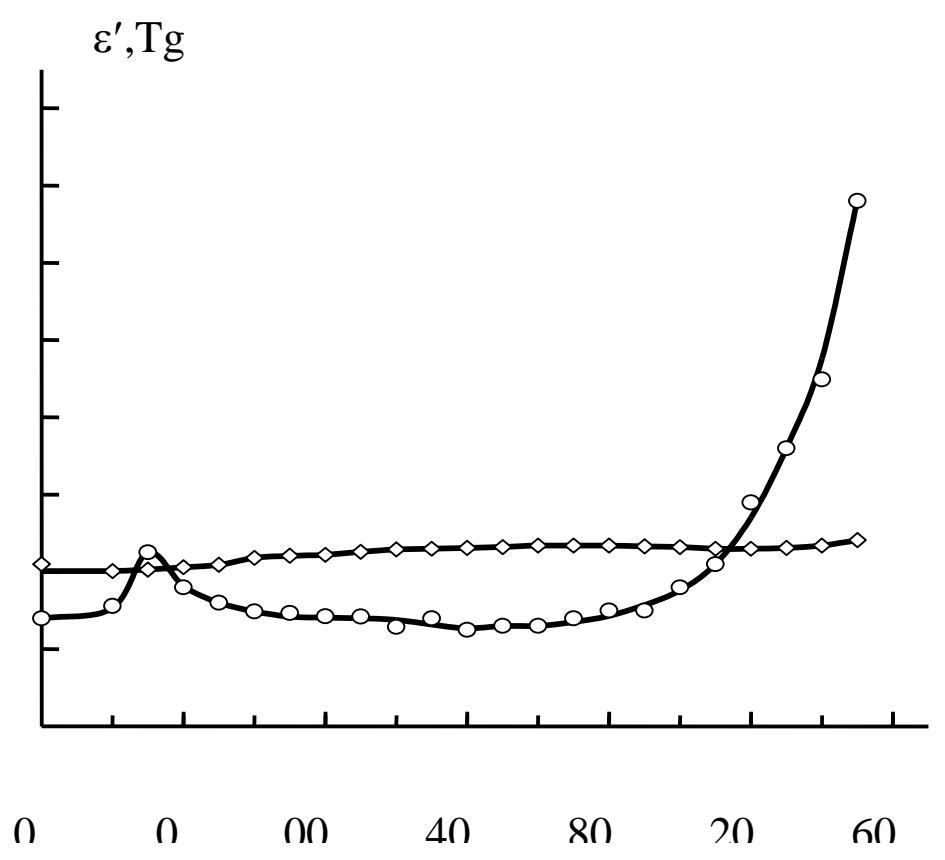

Рис. 1. Температурная зависимость диэлектрической проницаемости $\varepsilon^{\prime}(1)$ и тангенса угла диэлектрических потерь $\operatorname{tg} \delta(2)$ для образцов исходного ПБТ

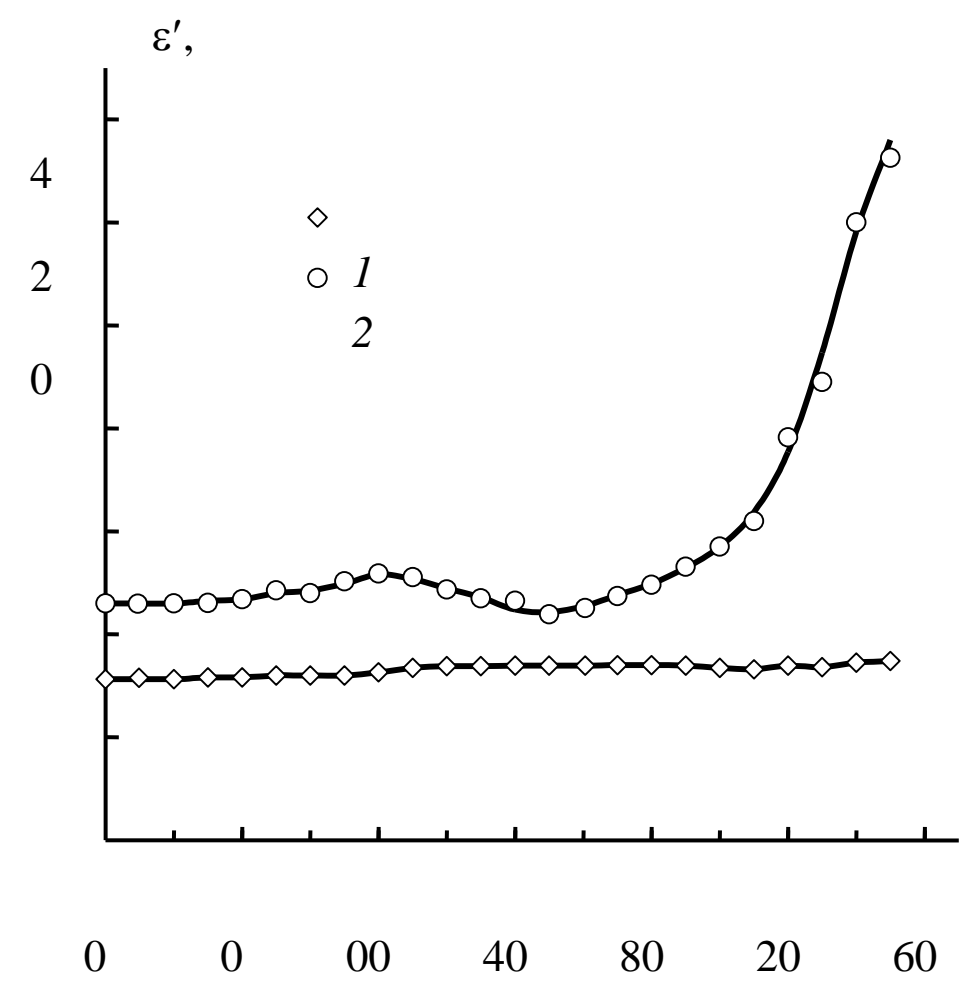

Рис. 2. Температурная зависимость диэлектрической проницаемости $\varepsilon^{\prime}(1)$ и тангенса угла диэлектрических потерь $\operatorname{tg} \delta(2)$ для исходных образцов композиций ПБТ + 2,5 масс. \% ПЭ 


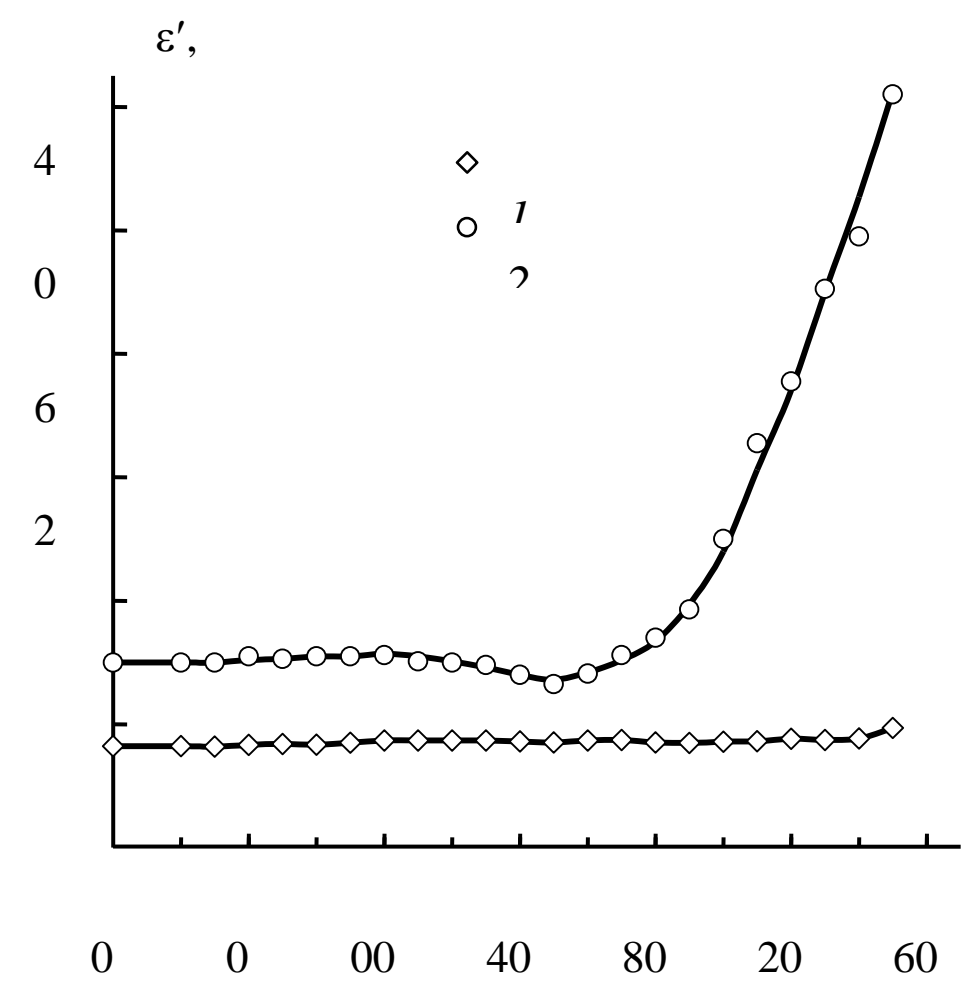

Рис. 3. Температурная зависимость диэлектрической проницаемости $\varepsilon^{\prime}(1)$ и тангенса угла диэлектрических потерь $\operatorname{tg} \delta(2)$ для исходных образцов композиций ПБТ + 5 масс. \% ПЭ

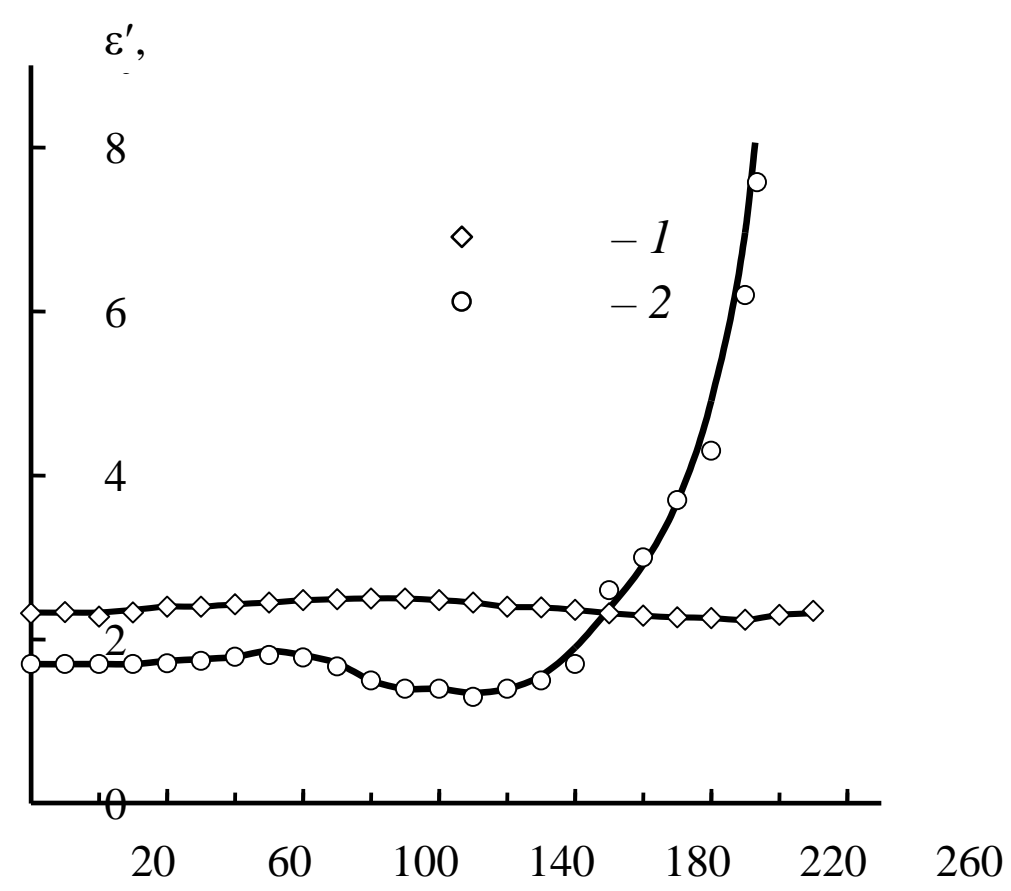

Рис. 4. Температурная зависимость диэлектрической проницаемости $\varepsilon^{\prime}(1)$ и тангенса угла диэлектрических потерь $\operatorname{tg} \delta(2)$ для исходных образцов композиций ПБТ + 10 масс. \% ПЭ 
Полибутилентерефталат сильнополярный полимер, диэлектрическую проницаемость можно определить дипольной ориентационной поляризациями. Диэлектрическая проницаемость полярных полимеров уменьшается с частотой и сложным образом зависит от температуры. Время установления дипольной ориентационной поляризации изменяется в зависимости от температуры на много порядков. Процессы ориентации диполей происходят на фоне хаотического теплового движения, поэтому полярные диэлектрики обладают существенной и немонотонной зависимостью $\varepsilon^{\prime}$ от температуры. С увеличением температуры Ван-дер-Ваальсовые связи ослабляются, вязкость уменьшается, что способствует поляризации и росту диэлектрической проницаемости. С возрастанием температуры увеличивается энергия теплового движения макромолекул, которое нарушает ориентацию, так как является хаотическим. Полностью кристаллическими или аморфными полимеры не существуют. Полимеры характеризуются наиболее устойчивой структурой плотная упаковка частиц и свободное пространство между этими частицами, резкое увеличение $\operatorname{tg} \delta$ с некоторого значения возможно связано с последним. Наверняка мы не можем сказать какие механохимические изменения претерпевает смесь ПБТ-ПЭ.

Следует отметить, что влиянию температуры, подвержены диэлектрическая проницаемость $\varepsilon^{\prime}$ и тангенса угла диэлектрических потерь $\operatorname{tg} \delta$ композиции ПБТ-ПЭ. Причинами этого возможно является зависимость характера движения связанных и свободных зарядов от этих факторов.

\section{Список литературы}

1. Акаева М.М., Машуков Н.И. Динамика изменения механических свойств полибутилентерефталата и композиций полибутилентерефталат полиэтилен в жидких агрессивных средах. // Известия Чеченского государственного университета. - 2016. - № 2. -С. 19-21.

2. Справочник по композиционным материалам, Под редакцией Д. Любинапер. с англ, А.Б. Геллера., М.М. Гельмонта. Кн.1 - М.: Машиностроение, - 1988. - 446 с.

3. Кулезнев В.М. Смеси полимеров - М.:Химия, - 1980. - 304 с.

4. Ioshi M., Maiti S.N., Miisra A. Poly(butylene terephthalate). High Density Polyethylene Alloys. 11. Mechanica Properties and Rheology. //J. of Appl. Polym. Sci. 1992. - V. 45. - P. 1837-1847.

5. Сажин Б.И., Лобанов А.М., Романовская О.С., Эйдельнант М.П. Койков С.Н. Электрические свойства полимеров, - Л.: Химия. - 1977. - 192 с. 